\title{
BMJ Global Health How overstated scientific claims undermine ethical principles in parenting interventions
}

\author{
Gabriel Scheidecker (D) ,,$^{1}$ Seth Oppong (D) , ${ }^{2}$ Nandita Chaudhary (i) , ${ }^{3}$ Heidi Keller ${ }^{4}$
}

To cite: Scheidecker G, Oppong S, Chaudhary N, et al. How overstated scientific claims undermine ethical principles in parenting interventions. BMJ Global Health 2021;6:e007323. doi:10.1136/ bmjgh-2021-007323

Received 1 September 2021 Accepted 12 September 2021

\section{SLinked}

- http://dx.doi.org/10.1136/ bmjgh-2021-006218

\section{Check for updates}

(c) Author(s) (or their employer(s)) 2021. Re-use permitted under CC BY-NC. No commercial re-use. See rights and permissions. Published by BMJ.

${ }^{1}$ Institute of Social and Cultural Anthropology, Free University of Berlin, Berlin, Germany ${ }^{2}$ Department of Psychology, University of Botswana, Gaborone, Botswana

${ }^{3}$ Human Development and Childhood Studies, University of Delhi, New Delhi, India ${ }^{4}$ Department of Human Sciences, Osnabrück University, Osnabrück, Germany

\section{Correspondence to} Dr Gabriel Scheidecker; gabriel.scheidecker@fu-berlin. de

\section{INTRODUCTION}

While parenting interventions are flourishing in low/middle-income countries (LMICs), their ethical challenges have rarely been considered. We therefore applaud Weber and colleagues ${ }^{1}$ for their contribution to a recent debate about the ethics of parenting interventions. ${ }^{2}{ }^{3}$ To apply the principles of beneficence, autonomy and justice to such interventions is certainly valuable, especially if 'respect for autonomy' includes consideration of additional ethical principles the targeted communities uphold. We also agree that 'recognising and integrating existing beliefs, practices, people, context and skills, in the programme design is crucial to fulfil the three principles. Finally, we agree most emphatically that there are considerable biases in the underlying research as it tends to 'only measure constructs that are valued from a western perspective'. ${ }^{1}$ However, it is our contention that the authors fail to apply these insights to the science on which they build their arguments. To fully acknowledge biases in the knowledge base of early childhood development (ECD), we argue, is a fundamental requirement to meet the principles they propose.

\section{EVIDENCE GAPS AND BIASES IN THE ECD LITERATURE}

Throughout the paper, Weber and colleagues refer to science to demonstrate the urgency and effectiveness of parenting interventions in LMICs, particularly to The Lancet's series Advancing Early Childhood Development. However, the research presented in this leading ECD publication is affected by the very same gaps Weber and colleagues raise. The basic research used to establish standards of childrearing and development as well as constructs to measure outcomes has been conducted overwhelmingly in Western
Summary box

The scientific constructs, standards and findings used to guide parenting interventions are overwhelmingly based on research in Euro-American settings, resulting in a Western bias when applied to communities in low/middle-income countries.

Ignoring this Western bias and overstating scientific evidence is a major obstacle to the fulfilment of ethical principles in parenting interventions because it fosters the imposition of external standards and prevents full recognition of local ways, needs and strengths that are known to be ecologically adaptive and socially valuable.

- We conclude that there is an urgent need to raise awareness for the Western biases in existing early childhood development research in order to increase sensitivity to local ways of childrearing that are different but not necessarily deficient, and to foster research that specifically tackles these weaknesses.

- Parenting interventions in LMICs need to carefully consider existing practices, beliefs and developmental goals in the targeted communities to ensure that ethical principles of beneficence, autonomy and justice are fulfilled.

countries. ${ }^{4}$ Even if applied research in LMICs is growing, it is still based on constructs produced in Western contexts. Research measuring 'culturally relevant skills and outcomes ${ }^{1}$ in the targeted communities is rarely included. Unfortunately, existing research from anthropology, cultural or indigenous psychology, that could help to narrow these gaps, is largely ignored. ${ }^{56}$

These research shortcomings and biases may be illustrated by one of the most fundamental claims of global ECD interventionsthat 250 million children under 5 years in LMICs are 'failing to achieve their developmental potential' and 'failing to thrive'. ${ }^{1}$ First of all, we should notice that it is not simply an empirical issue whether children are thriving or achieving their developmental potential. De facto, it is determined by setting 
developmental goals 'that are valued from a Western perspective', ${ }^{1}$ ignoring the well-known fact that such goals vary greatly across sociocultural contexts. ${ }^{7}$

Even if we accept externally imposed goals, the problem of assessment remains: the number of 250 million failing children is simply derived from the estimated prevalence of stunting and poverty. ${ }^{8}$ The few actual assessments of developmental outcomes in LMICs raise again the question of adequate constructs. Common cognitive tests rely on specific constructs of intelligence that have been shown to deviate clearly from conceptions in African and other settings. ${ }^{910}$ Low school achievement is not less problematic as an indicator of cognitive deficits since it may simply reflect low school quality. Another indicator, 'inadequate home stimulation', which is claimed to compromise proper cognitive development of $53 \%$ of Africa's young children, ${ }^{11}$ deserves a closer look, because it serves specifically to justify parenting interventions.

Home stimulation is usually measured by parent-child play or talk and the availability of toys or books in the home. ${ }^{12}$ This operationalisation may adequately capture the amount of stimulation young children receive in an urban, nuclear-family setting where they stay mostly in an enclosed space with few social partners. However, it may miss the real amount of stimulation children experience in a rural, extended-family setting where they spend most of the day outside having access to a much broader material and social world. In such settings, care is typically distributed across a group of relatives. ${ }^{13}$ Furthermore, the functions of early childhood development are often distributed complementarily, so that siblings and cousins are primary play and conversational partners while parents take care of other needs. ${ }^{14}$ Thus, measuring stimulation through a single adult caregiver may severely underestimate the real amount of stimulation children experience in LMICs. We can only imagine the results if the rural, extended-family scenario would have been operationalised as the standard: urban, nuclear-family children would probably appear to live in a socially and materially deprived world, in which toys must compensate for the real world and parents for a bunch of play partners.

\section{HOW OVERSTATED SCIENTIFIC CLAIMS UNDERMINE ETHICAL PRINCIPLES}

Overstating scientific claims while downplaying evidence gaps and biases undermines the good intentions to meet ethical principles. Beneficence presupposes that assumed benefits outweigh possible harm. Therefore, universal vaccination, which Weber and colleagues choose as a model, is preceded by careful examination of side effects. However, negative side-effects of parenting interventions in LMICs are rarely examined in evaluation research. Some side-effects are quite obvious, however: the widely publicised claim that poor children and, by implication, their community members, suffer from cognitive and socio-emotional deficits devalues LMIC populations and legitimises negative stereotypes. Since this claim is unjustifiably presented as evidence-based, it must be considered an instance of epistemological violence. ${ }^{1516}$

Autonomy is respected, according to Weber and colleagues, if 'facilitators encourage community members to consider their existing practices in light of available scientific evidence'. ${ }^{1}$ For community members to make truly informed decisions 'the science presented must be evidence-based and generalisable to the local context'. However, this is often not the case as Weber and colleagues acknowledge: 'If evidence grows that such programmes benefit those most in need ... then we will be ethically obliged to provide the information'. ${ }^{1}$ We would like to add that we should not pretend to already have the evidence, because we do not. Unjustified evidence claims skews people's autonomous decisions-similar to a missionary claiming to simply inform people about 'hell' while letting them freely decide whether to convert.

In the name of justice, Weber and colleagues argue, we are called upon to promote parenting interventions, since 'to do nothing' ${ }^{1}$ would mean to preserve the status quo and perpetuate poverty through poor cognitive development. However, this argument rests on three questionable assumptions: (1) that poor cognitive development is in fact the root of poverty, (2) that LMIC communities are unable to change without external interventions and (3) that ECD interventions are the only means to do something. The first assumption rests on poor science as outlined earlier; for the other two no evidence is provided at all. Nevertheless, we agree that we should do something about poverty—but there are other ways of understanding and improving the condition of disadvantaged people. In fact, Weber and colleagues hint to such an alternative approach which we discuss next.

\section{OUTLOOK}

Referring to cultural psychologists and anthropologists, they state that childrearing practices in LMICs may become ineffective when the conditions change and new developmental demands such as formal education emerge. Such a mismatch is possible, although it needs to be determined in each case since, to use the central phrase of the target article, 'Africa is not a museum, and communities are able to adapt to new conditions. The underlying ecocultural approach has several important implications: first, preaching a set of universally valid 'scientific best practices', ${ }^{1}$ appears problematic because what is best depends on ecocultural conditions that are never the same everywhere. Second, low school achievement cannot simply be ascribed to deficits on the part of the children but rather to a mismatch between home and school learning environment. Finally, such an approach points to multiple solutions, since a mismatch can be solved on both sides. School curricula in LMICs are often burdened with a colonial legacy and poorly adapted to local requirements. ${ }^{17}$ Thus, decolonising schools would occur as an alternative to a neo-colonial expansion of 
interventions into the domains of early childhood and family life. Balancing structural causes of disadvantage and inequality with human agency is certainly relevant for all three ethical principles.

\section{CONCLUSION}

Excessive scientific claims in the ECD field represent a major ethical challenge that can undermine good intentions to live up to ethical principles. Hence, we recommend a more modest approach that is conscious of scientific biases and potential epistemological violence, and that fully considers their implications on all aspects of ECD practice. Such a stance is crucial to realise the recommendations of Weber and colleagues to sincerely consider the values and ways of the targeted communities-not just to make them adopt precast programmes. Finally, such an approach would foster research that specifically tackles the scientific biases and, thus, helps to improve the knowledge base of ECD more effectively. As a starting point, we suggest the consideration of research from anthropology, cultural psychology, indigenous psychology and other disciplines with a long-standing focus on the diversity of childrearing and development in LMICs.

Acknowledgements We acknowledge support by the Open Access Publication Fund of Freie Universität Berlin.

Contributors GS conceived of and drafted the paper. SO, NC and HK contributed to framing of key points. All authors contributed to editing and finalising the paper.

Funding The authors have not declared a specific grant for this research from any funding agency in the public, commercial or not-for-profit sectors.

Competing interests None declared.

Patient consent for publication Not applicable.

Ethics approval This study did not receive nor require ethics approval, as it does not involve human and animal participants.

Provenance and peer review Not commissioned; internally peer reviewed. Data availability statement There are no data in this work.

Open access This is an open access article distributed in accordance with the Creative Commons Attribution Non Commercial (CC BY-NC 4.0) license, which permits others to distribute, remix, adapt, build upon this work non-commercially, and license their derivative works on different terms, provided the original work is properly cited, appropriate credit is given, any changes made indicated, and the use is non-commercial. See: http://creativecommons.org/licenses/by-nc/4.0/.

\section{ORCID iDs}

Gabriel Scheidecker http://orcid.org/0000-0002-4461-1773

Seth Oppong http://orcid.org/0000-0003-1977-5538

Nandita Chaudhary http://orcid.org/0000-0002-9584-3793

\section{REFERENCES}

1 Weber AM, Diop Y, Gillespie D, et al. Africa is not a museum: the ethics of encouraging new parenting practices in rural communities in low-income and middle-income countries. BMJ Glob Health 2021;6:e006218.

2 Morelli G, Quinn N, Chaudhary N, et al. Ethical challenges of parenting interventions in low- to middle-income countries. $J$ Cross Cult Psychol 2018;49:5-24.

3 Morelli G, Bard K, Chaudhary N, et al. Bringing the real world into developmental science: a commentary on Weber, Fernald, and Diop (2017). Child Dev 2018;89:e594-603.

4 Scheidecker G, Chaudhary N, Keller H. Poor brain development in the global South? challenging the evidence base of early childhood interventions In press.

5 Chaudhary N, Sriram S. Psychology in the "backyards of the world": experiences from India. J Cross Cult Psychol 2020;51:113-33.

6 Oppong S. Overcoming obstacles to a truly global psychological theory, research, and praxis in Africa. $J$ of Psychol Afr 2019;29:292-300.

7 Keller H. Culture and development: a systematic relationship. Perspect Psychol Sci 2017;12:833-40.

8 Grantham-McGregor S, Cheung YB, Cueto S, et al. Developmental potential in the first 5 years for children in developing countries. Lancet 2007;369:60-70.

9 Oppong S. Towards a model of valued human cognitive abilities: an African perspective based on a systematic review. Front Psychol 2020;11:3381.

10 Serpell R. Intelligence and culture. In: Handbook of intelligence. Cambridge University Press, 2000: 549-77.

11 Lu C, Cuartas J, Fink G, et al. Inequalities in early childhood care and development in low/middle-income countries: 2010-2018. BMJ Glob Health 2020;5:e002314.

12 Walker SP, Wachs TD, Grantham-McGregor S, et al. Inequality in early childhood: risk and protective factors for early child development. Lancet 2011;378:1325-38.

13 Weisner TS, Gallimore R. My brother's keeper: child and sibling caretaking. Curr Anthropol 1977;18:169-90 https://www.journals. uchicago.edu/doi/abs/10.1086/201883

14 Scheidecker G. Parents, caregivers, and Peers: patterns of complementarity in the social world of children in rural Madagascar. Curr Anthropol in press.

15 Oppong S. When something dehumanizes, it is violent but when it elevates, it is not violent. Theory Psychol 2020;30:468-72.

16 Teo T. What is epistemological violence in the empirical social sciences? Soc Personal Psychol Compass 2010;4:295-303.

17 Shizha E. Reclaiming our Indigenous voices: the problem with postcolonial sub-Saharan African school curriculum. J. Indig. Soc. Dev 2013;2:1-18 https://journalhosting.ucalgary.ca/index.php/jisd/ article/view/63052 